\title{
Changes in the cellular composition of the spleen and pronephros of carp Cyprinus carpio infected with the blood fluke Sanguinicola inermis (Trematoda: Sanguinicolidae)
}

\author{
D. T. Richards ${ }^{1}$, D. Hoole ${ }^{1}$, J. W. Lewis ${ }^{2}$, E. Ewens ${ }^{2}$, C. Arme ${ }^{1}$ \\ ${ }^{1}$ Department of Biological Sciences, Keele University, Keele, Staffordshire ST5 5BG, United Kingdom \\ ${ }^{2}$ Department of Biology, Royal Holloway, University of London, Egham, Surrey TW20 0EX, United Kingdom
}

\begin{abstract}
Ultrastructural changes in cells of carp Cyprinus carpio (L.) spleen and pronephros were studied after experimentally infecting each fish with 500 Sanguinicola inermis cercariae. Cells were identified morphologically and counted within transmission electron microscope preparations of tissues from carp killed 5 and 9 wk post-infection. Results were compared with cell counts in uninfected controls. In the spleen, parasitism induced significant reductions of erythrocytes $(p<0.001)$, neutrophils $(p<0.01)$ and eosinophils $(p<0.001)$ and significant increases of thrombocytes ( $<0.001)$ and macrophages $(p<0.001)$. In the pronephros, following infection, there were significant reductions of erythrocytes $(p<0.05)$, lymphocytes $(p<0.05)$, thrombocytes $(p<0.05)$ and eosinophils $(p<0.001)$ and significant increases of macrophages $(p<0.001)$ and neutrophils $(p<0.001)$. These changes are believed to be associated with the presence of adult $S$. inermis in the host vascular system and/or eggs which become entrapped in host tissues.
\end{abstract}

KEY WORDS: Sanguinicola inermis · Cyprinus carpio - Lymphoid organs

\section{INTRODUCTION}

Sanguinicola inermis Plehn, 1905 is an important pathogen of carp Cyprinus carpio (L.) (Iqbal \& Sommerville 1986, Lee 1990, Sommerville \& Iqbal 1991, Kirk \& Lewis 1993). Adult flukes mature in the vascular system of the host, where their presence may result in obstruction of blood flow (Lee 1990). Eggs are shed from $24 \mathrm{~d}$ post-infection (p.i.) in fish maintained at $20^{\circ} \mathrm{C}$ (Lee, 1990; Kirk \& Lewis, 1992), although fluke maturation may be temperature dependent, as sexual maturity does not occur until 60 days p.i. in fish maintained at 15 to $18^{\circ} \mathrm{C}$ (Iqbal 1984 , Sommerville \& Iqbal 1991, Kirk \& Lewis 1993). The presence of eggs and miracidia can result in extensive damage to host tissue (Lee 1990). In the gills, the occurrence of entrapped eggs and migrating miracidia results in a reduction of the respiratory surface due to granuloma formation and fusion between primary and secondary gill lamellae (Lee 1990). Light microscopical observations have shown that collagenous connective tissue, laid down by fibroblasts and host inflammatory cells, encapsulates entrapped eggs (Lee 1990). Recent ultrastructural studies by Richards et al. (1994) have revealed that eosinophils, neutrophils and macrophages accumulate in the cellular response within the mesonephros of infected carp.

Previous studies on tapeworm infections of fish (Taylor \& Hoole 1989) have shown that parasitism alters the cellular composition of the pronephros and spleen of cyprinid fish. The present investigation has been undertaken to determine the effects of Sanguinicola inermis infection on the lymphoid organs of experimentally infected carp, and forms part of a more extensive study on the interaction between the parasite and carp leucocytes. 


\section{MATERIALS AND METHODS}

Maintenance of snails and carp were as previously described by Richards et al. (1994).

Carp ( 3 mo old) were each exposed to 500 Sanguinicola inermis cercariae for $1 \mathrm{~h}$ and a control group was sham exposed. Six infected carp were killed at 5 wk p.i. and 6 at 9 wk p.i. The presence of $S$. inermis was confirmed by examining the heart and its associated vasculature for adult flukes and the gills and kidney (mesonephros) for eggs. Numbers of adult flukes in the vascular system and eggs present in the filaments of each gill arch and in one-half of the mesonephros of each fish were recorded. Controls were killed $9 \mathrm{wk}$ after being sham exposed.

The spleen and pronephros of each fish were removed, cut into $1 \mathrm{~mm}^{3}$ blocks and fixed in $3 \%$ glutaraldehyde in 0.1 M Sorenson's buffer ( $\mathrm{pH} 7.2)$. After postfixation in $1 \%$ osmium tetroxide in $0.1 \mathrm{M}$ Sorenson's buffer ( $\mathrm{pH}$ 7.2), tissues were dehydrated in a graded series of acetone and embedded in Spurr's resin. Ultrathin sections were stained in uranyl acetate and Reynold's lead citrate. Observations were carried out on a Jeol JEM 100 CR II transmission electron microscope. Cells were identified on the basis of their morphological features and on the descriptions given for their respective granules by Cenini (1984).

From both the spleen and pronephros of each fish, the numbers of cells within 5 randomly selected areas of $0.01 \mathrm{~mm}^{2}$ were counted. The differences between numbers of cells in control and infected groups were tested for significance using a Student's t-test and Wilcoxon Rank Sum Test (Bailey 1985). Regression analyses were used to determine if any relationship existed between numbers of flukes and eggs recovered and numbers of host cells in the spleen and pronephros.

\section{RESULTS}

Cell populations of the spleen (Fig, 1) and pronephros (Fig. 2) of carp included erythrocytes, lymphocytes, thrombocytes, macrophages, neutrophils and eosinophils.

\section{Recovery of flukes}

The numbers of adult flukes and eggs found in infected fish varied. Only a relatively low percentage ( $<3.6 \%$ ) of cercariae developed into mature adult flukes, although eggs were recovered from all fish examined. No adult flukes or eggs were recovered from control fish. Mean numbers of adult flukes recovered from infected fish were 5.3 (range 1 to 18 ) at 5 wk p.i. and 2.2 (range 1 to 7 ) at 9 wk p.i. Mean numbers of eggs recovered in the gills and kidneys were 18.3 (range 7 to 43 ) and 5.0 (range 2 to 7 ) respectively at 5 wk p.i. and 7.8 (range 4 to 13) and 49.2 (range 4 to 169) respectively at 9 wk p.i.

Regression analysis revealed that in the spleens of fish killed 5 wk p.i., as numbers of adult Sanguinicola inermis increased, there was a significant increase in lymphocytes $(r=0.89, p<0.05)$ and a decrease in eosinophils $(r=-0.87, p<0.05)$. In the pronephros of fish killed 9 wk p.i., there was significant positive correlation between erythrocytes $(\mathrm{r}=0.88$ : $\mathrm{p}<0.05)$ and adult flukes and between lymphocytes ( $r=0.88, p<0.05)$ and the numbers of eggs in the gills. When the results obtained from fish killed at 5 and 9 wk p.i. were combined, as numbers of adult worms increased there were significant increases of lymphocytes $(r=0.73$, $\mathrm{p}<0.01$ ) and thrombocytes $(\mathrm{r}=0.75, \mathrm{p}<0.01)$ and $\mathrm{a}$ decrease of neutrophils $(r=-0.58, p<0.05)$ in the pronephros.

No other significant correlations were found between numbers of adults and/or eggs recovered from each fish and the number of cach of the respective host cell types within the spleen or pronephros.

\section{Differential cell counts}

Differences in the ultrastructural appearances of the spleen and pronephros were related to differences in the numbers of each cell type observed in control and infected fish.

In the spleen (Fig. 3a), erythrocytes predominated in uninfected fish (Fig. 1a) but parasitism induced a significant reduction in their number $(p<0.001$; Fig. $1 b)$. There were also significantly fewer neutrophils $(p<0.01)$ and eosinophils $(p<0.001)$ in infected fish, whereas there were significantly more macrophages $(\mathrm{p}<0.001)$ and thrombocytes $(\mathrm{p}<0.001)$. In addition, there were significantly fewer neutrophils $(p<0.01)$ and eosinophils $(\mathrm{p}<0.001)$ at $9 \mathrm{wk}$ p.i. when compared with those at $5 \mathrm{wk}$ p.i. Although numbers of Iymphocytes were lower in infected fish, the differences were not significant $(p>0.05)$.

In the pronephros (Fig. 3b), leucocytes, and in particular neutrophils, predominated in uninfected fish (Fig. 2a). Infected fish had significantly higher counts of neutrophils ( $p<0.001$; Fig. 2b) and macrophages $(p<0.001)$ and significantly fewer erythrocytes $(p<0.05)$, lymphocytes $(p<0.05)$, thrombocytes $(p<0.05)$ and eosinophils $(p<0.001)$. Between 5 and 9 wk p.i. there were significant increases in macrophages ( $p<0.001)$ and neutrophils $(p<0.001)$, and a decrease in eosinophils $(p<0.05)$ 


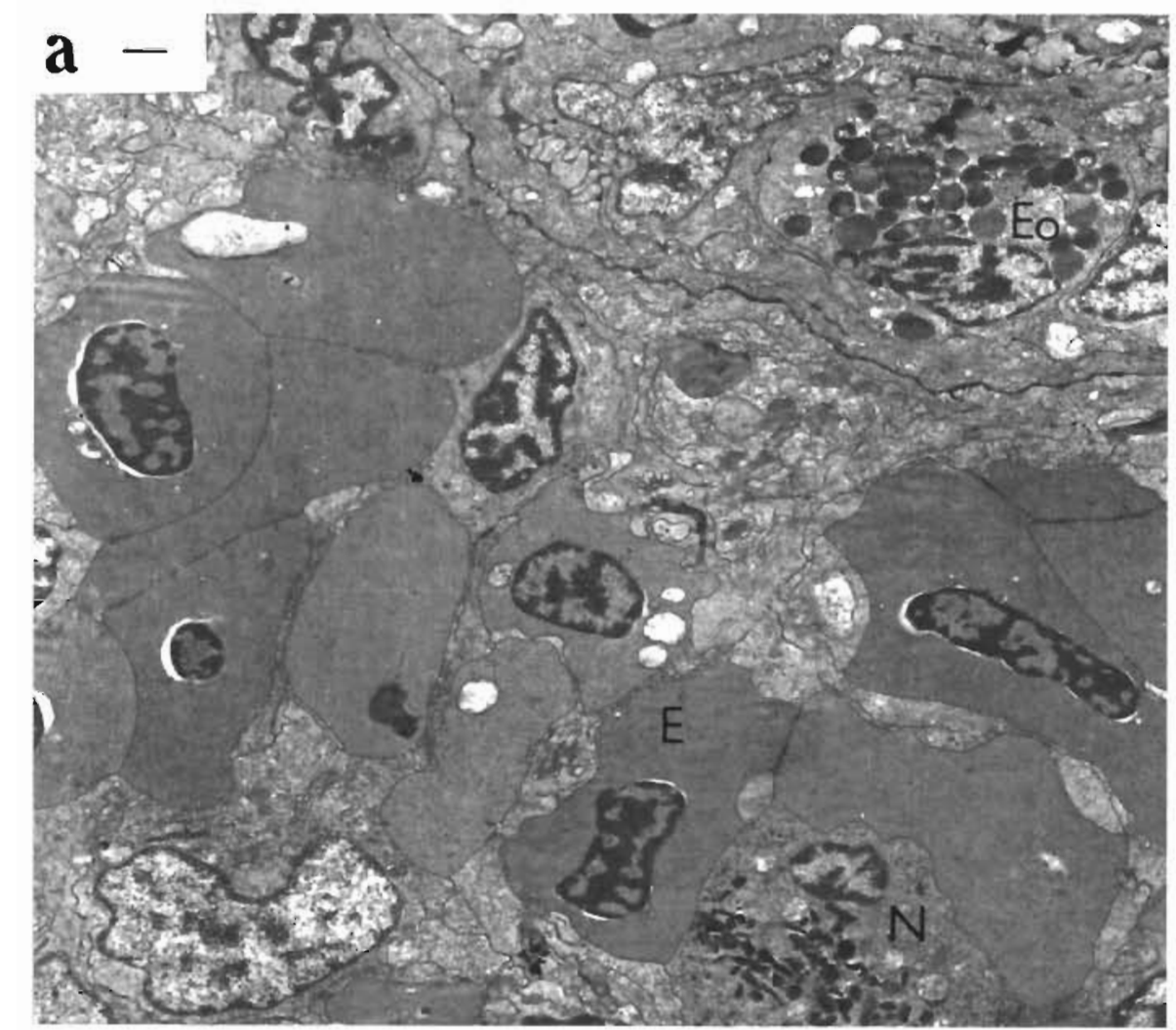

Fig. 1. Cyprinus carpio. Ultrastructure of the spleen in (a) uninfected control and (b) infected carp 9 wk post-infection. E: erythrocyte Eo: eosinophil; $\mathrm{N}$ : neutrophil; $\mathrm{T}$ : thrombocyte. Scale bars $=1 \mu \mathrm{m}$

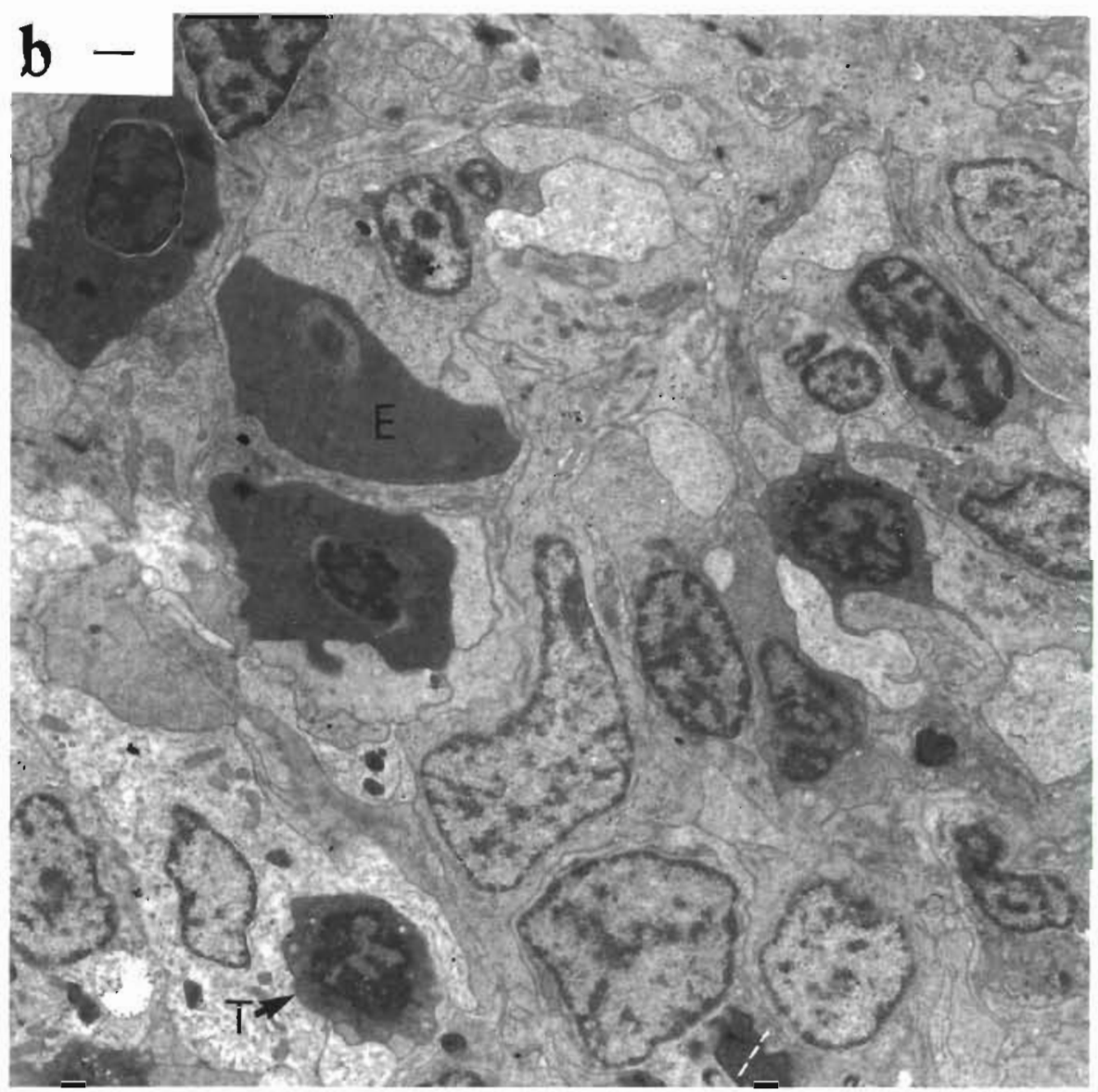



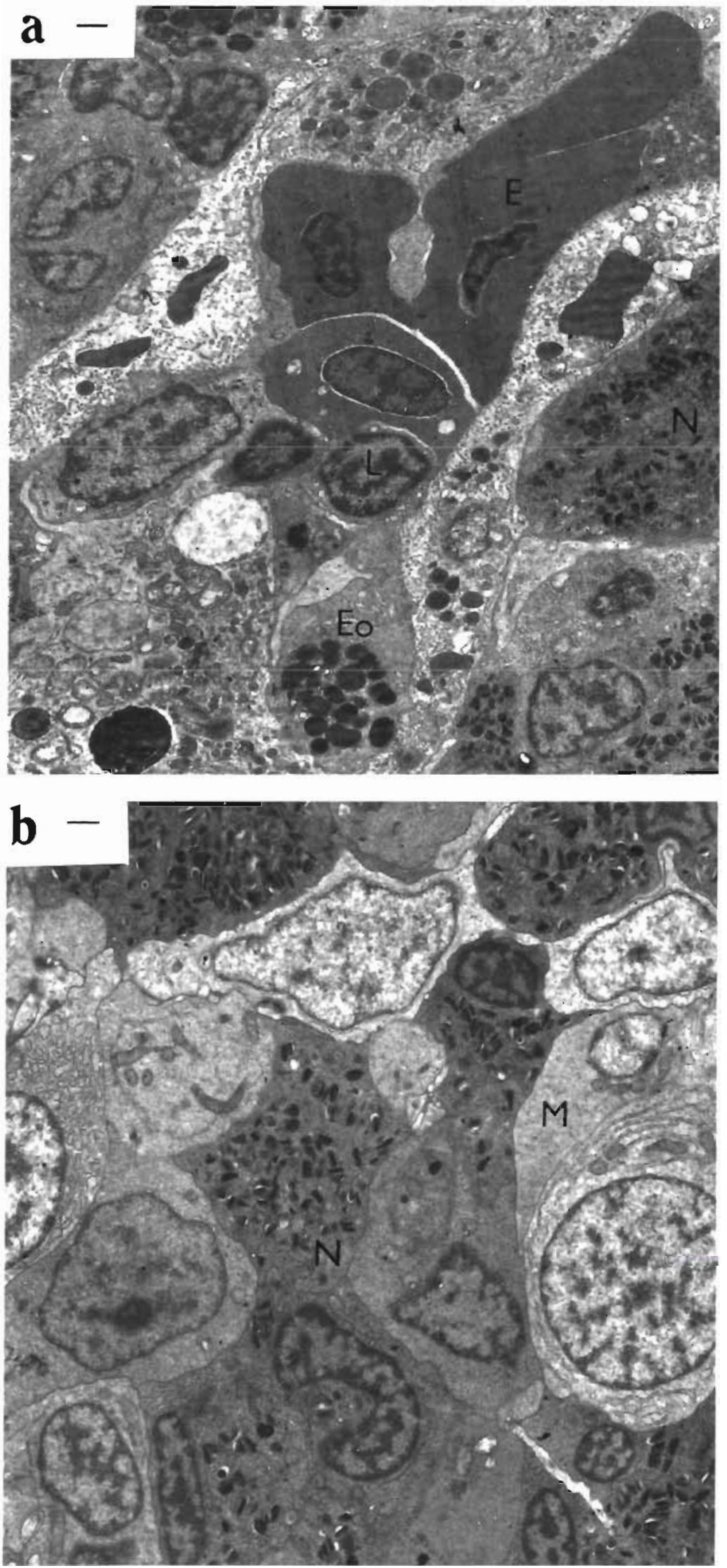

\section{DISCUSSION}

The occurrence of erythrocytes, lymphocytes, thrombocytes, macrophages and granulocytes within the lymphoid organs of teleosts has been well documented (Corbel 1975, Ellis 1977, 1989. Rowley et al. 1988).

Previous studies on fish have shown that variations in numbers of these cell types occur during stress (Peters \& Schwarzer 1985), by affecting hormonal balance and the effectiveness of the immune system (Ellis 1981). Stress-induced changes in the spleen and head kidney of rainbow trout Onrorhynrhus mykiss for example, include decreases in lymphocytes and destruction of erythrocytes and increases in neutrophils and macrophages (Peters \& Schwarzer 1985).

In addition to stress, which may itself increase the susceptibility of fish to disease, parasitism has a significant effect on the cellular composition of lymphoid organs. Previous studies on the effects of parasitic infection on fish lymphoid organs have tended to focus on responses to either bacteria or protozoans, or to injected soluble or particulate antigens (Neale \& Chavin 1971, Ferguson 1976, Bach et al. 1978, Dyková \& Lom 1979, Ellis 1980, Secombes \& Manning 1982, Secombes et al. 1982, Bruno \& Munro 1986. Woo 1987). A common feature of responses to these agents was splenomegaly, attributed to proliferation of lymphocytes and granulocytes (Secombes \& Manning 1982, Secombes et al. 1982) or retention of erythrocytes (Bruno \& Munro 1986)

In the present study, however, one of the most marked features of the effects of parasite infection was the significant reduction in numbers of erythrocytes in the spleens of infected fish. Taylor \& Hoole (1989) demonstrated significant decreases in the spleen weights of roach Rutilus rutilus infected with the plerocer-

Fig. 2. Cyprinus carpio. Ultrastructure of the pronephros in (a) uninfected control and (b) infected carp 9 wk post-infection. E: erythrocyte; Eo: eosinophil; $N$ : neutrophil; L: lymphocyte; M: macrophage; Scale bars $=1 \mu \mathrm{m}$ 

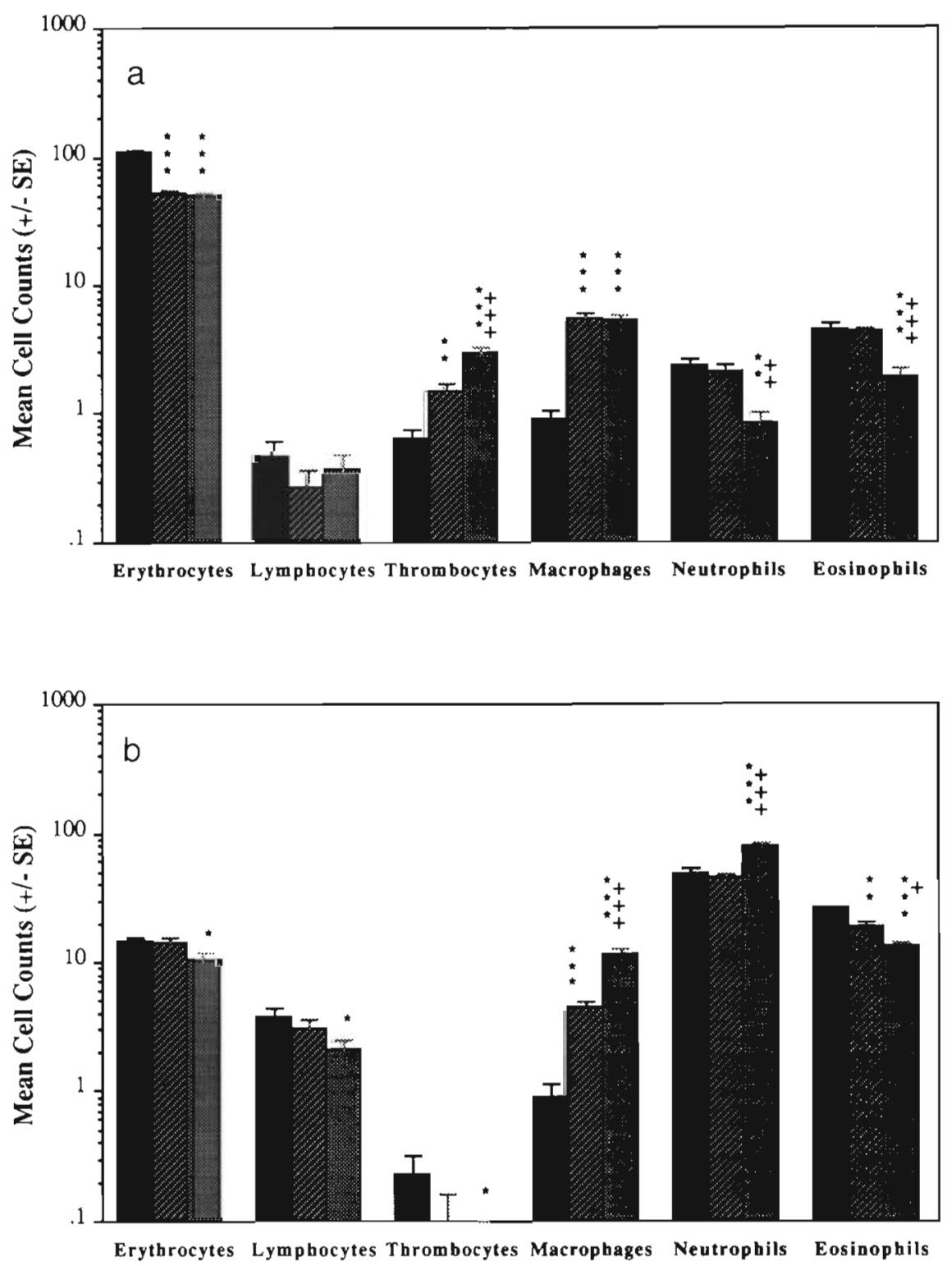

Fig. 3. Cyprinus carpio. Cell counts in (a) spleen and (b) pronephros of carp infected with Sanguinicola inermis ( 5 wk post-infection (p.i.); : 9 wk p.i.). Bars represent mean values (+SE) from a total of 30 randomly selected areas $\left(0.01 \mathrm{~mm}^{2}\right.$ ) from the tissues of 6 fish. $p<0.05, \cdots p<0.01, \cdots p<0.001$ for sionificant differences between numbers of cells in controls and infected fish; $+p<0.05,++p<0.01,+++p<0.001$ for significant differences between numbers of cells in infected fish at 5 wk $p . i$. and 9 wk p.i.

coid of Ligula intestinalis. As in the present study, this phenomenon was attributed to a marked and significant reduction in the number of erythrocytes in the spleens of infected fish. A similar reduction has also been observed in the spleen of cutthroat trout infected with plerocercoids of Diphyllobothrium cordiceps (Otto \& Heckmann 1984).

Thrombocytes, which are associated with coagulation, increased significantly in infected fish in the present study. Adult Sanguinicola inermis in the vas- cular system cause hyperplasia of endothelial linings and blockage of vessels, and entrapped eggs induce ischaemia and the development of necrotic areas, leading to rupture of vessels in the gills and other host tissues (Lee 1990). Increases of thrombocytes in fish infected with $S$. inermis may, therefore, be related to increased haemorrhaging associated with the presence of adult flukes and eggs within damaged blood vessels and tissues.

Lymphocytes, which are commonly found in the cir- 
culation, lymphoid organs, especially the thymus and kidney, and in other tissues, increase in number during an inflammatory response (Ellis 1977, 1989, Secombes et al. 1982, Tatner 1985, Rowley et al. 1988). As noted in previous studies, these cells tend to be more numerous in the kidney than in the spleen (Ellis 1989). Although there were significant increases in numbers of lymphocytes with increasing numbers of adult flukes at 5 wk p.i., and with eggs at 9 wk p.i., their numbers in the pronephros declined significantly in infected fish by 9 weeks p.i. This latter phenomenon is perhaps surprising given that, as noted above, lymphocytes generally increase during an inflammatory response. However, counts of lymphocytes in the pronephros and spleen were first made some $5 \mathrm{wk}$ after the initial infection, and it is possible that an increase in their numbers relative to the controls occurred prior to 5 wk p.i. Previous studies have shown, for example, that numbers of antibody-producing cells in carp maintained at $20^{\circ} \mathrm{C}$, peaked 10 to $15 \mathrm{~d}$ after antigenic stimulation with sheep red blood cells (SRBC), and that their numbers then decreased (Rijkers et al. 1980). In addition, numbers of plaque-forming cells in the spleen and pronephros of roach that were specific to tegumental antigens of the plerocercoid of Ligula intestinalis were found to peak only $6 \mathrm{~d}$ after injection with antigen-coated SRBC (Williams \& Hoole 1992). Numbers of these cells then decreased to control values by $14 \mathrm{~d}$ after injection.

Previous studies by Richards et al. (1994) showed that eosinophils predominated in the inflammatory response of carp to Sanguinicola inermis, 3 to $4 \mathrm{wk}$ p.i., and suggested that their initial migration to the egg surface occurred in response to surface antigens or to substances diffusing out of the egg. Eosinophils subsequently decreased in number at the sites of inflammation from 4 to $5 \mathrm{wk}$ p.i. as there was infiltration and accumulation of neutrophils and macrophages around the eggs. During the present study, significantly fewer eosinophils were found in the pronephros of infected fish by $5 \mathrm{wk}$ p.i. It is therefore possible that, as suggested for the lower levels of lymphocytes in infected fish, eosinophils may be more prominent in the lymphoid organs prior to $5 \mathrm{wk}$ p.i., when they also appear to be more important in the inflammatory response to entrapped eggs. It is also possible that lower numbers of certain cell types in the lymphoid organs may be related to migration of the respective cells out of these organs and into sites of inflammation

Richards et al. (1994) also postulated that accumulation and degranulation of eosinophils promoted infiltration by neutrophils and monocytes which were the predominant cell types observed from 4 to $10 \mathrm{wk}$ p.i. It was further suggested that these latter cell types sub- sequently phagocytosed damaged tissues and released products such as reactive oxygen species, which have often been shown to exert toxic effects on parasite surfaces (Nash et al. 1987, Graham \& Secombes 1988 Plytycz et al. 1989). Encapsulation of entrapped eggs was first observed 5 to $6 \mathrm{wk} \mathrm{p.i,} \mathrm{and} \mathrm{this} \mathrm{was} \mathrm{subse-}$ quently followed by structural damage to the egg and miracidium at 8 to $9 \mathrm{wk}$ p.i. Throughout this latter period, macrophages and neutrophils accumulated around entrapped eggs. This phenomenon appears to be reflected in the results of the present study, which demonstrated significant increases of neutrophils in the pronephros and of macrophages in both lymphoid organs.

Fish leucocytes have previously been shown to be stimulated by parasites, or cxtracts of parasites. Taylor \& Hoole (1993), for example, demonstrated increased in vitro polarization and chemotactic responses of roach and gudgeon Gobio gobio pronephric leucocytes to the presence of extracts of Ligula intestinalis. These responses were enhanced in the presence of serum and it was suggested that host-derived factors such as complement may also be involved in leucocyte chemoattraction to the parasite. Further in vitro studies are in progress to determine the functional role of the leucocyte types within the inflammatory response of carp to Sanguinicola inermis.

Acknowledgements. The authors thank Mr Ian Wright for technical assistance and the A.F.R.C. for financial support (Grant Number AG111/622)

\section{LITERATURE CITED}

Bach, R., Chen, P. K., Chapman, G. B. (1978). Changes in the spleen of the channel catfish Ictalurus punctatus Rafinesque, induced by infection with Aeromonas hydrophila. J. Fish Dis. 1: 205-217

Bailey, N. J. T (1985). Statistical methods in biology, 2nd edn. Hodder \& Stoughton, London

Bruno, D. W., Munro, A. L. S. (1986). Haematological assessment of rainbow trout, Salmo gairdneri Richardson. and Atlantic salmon, Salmo salar L., infected with Renibacterium salmoninarum. J. Fish Dis. 9: 195-204

Cenini, P. (1984). The ultrastructure of leucocytes in carp (Cyprinus carpio). J. Zool. Lond. 204: 509-520

Corbel, M. J. (1975). The immune response in fish: a review J. Fish Biol. 7: 539-563

Dyková, I., Lom, J. (1979). Histopathological changes in Trypanosoma danilewskyi Laveran \& Mesnil, 1904 and Trypanoplasma borelli Laveran \& Mesnil, 1902 infections of goldfish, Carassius auratus (L.). J. Fish Dis. 2: 381-390

Ellis, A. E. (1977). The leucocytes of fish: a review. J. Fish Biol. 11: $453-491$

Ellis, A. E. (1980). Antigen-trapping in the spleen and kidney of the plaice Pleuronectes platessa (L.). J. Fish Dis. 3: 413-426 
Ellis, A. E. (1981). Stress and the modulation of defence mechanisms in fish. In: Pickering, A. D. (ed.) Stress and fish. Academic Press, London, p. 147-169.

Ellis, A. E. (1989). The immunology of teleasts. In: Roberts, R. J. (ed.) Fish pathology. Balliere-Tindall, London, p. $135-152$

Ferguson, H. W. (1976). The relationship between ellipsoids and melano-macrophage centres in the spleen of turbot (Scophthalmus maximus). J. comp. Pathol. 86: 377-380

Graham, S., Secombes, C. J. (1988). The production of a macrophage-activating factor from rainbow trout Salmo gairdneri leucocytes. Immunology 65: 293-297

Iqbal, N. A. M. (1984). Studies on Sanguinicola inermis Plehn, 1905 from cultured carp (Cyprinus carpio) in Britain. Ph.D. thesis, Institute of Aquaculture, University of Stirling

Iqbal, N. A. M., Sommerville, C. (1986). Effects of Sanguinicola inermis Plehn, 1905 (Digenea: Sanguinicolidae) infection on growth performance and mortality in carp, Cyprinus carpio L. Aquacult. Fish. Mgmt 17: $117-122$

Kirk, R. S., Lewis, J. W. (1992). The laboratory maintenance of Sanguinicola inermis Plehn, 1905 (Digenea: Sanguinicolidae). Parasitology 104: 121-127

Kirk, R. S., Lewis, J. W. (1993). The life-cycle and morphology of Sanguinicola inermis Plehn, 1905 (Digenea: Sanguinicolidae). Syst. Parasitol. 25: 125-133

Lee, R. S. (1990). The development of Sanguinicola inermis Plehn, 1905 (Digenea: Sanguinicolidae) in the common carp Cyprinus carpio L. Ph.D. thesis, Royal Holloway \& Bedford New College, University of London

Nash, K. A., Fletcher, T. C., Thomson, A. W. (1987). Effect of opsonization on the oxidative metabolism of plaice (Pleuronectes platessa L.) neutrophils. Comp. Biochem. Physiol. 86: 31-36

Neale, N. L., Chavin W. (1971), Lymphocytic tissue alterations during the primary immune response of the goldfish (Carassius auratus L.). Mich. Academ. 3: 23-30

Otto, T. N., Heckmann, R. A. (1984). Host tissue response for trout infected with Diphyllobothrium cordiceps larvae. Great Basin Nat. 44: 125-132

Peters, S., Schwarzer, R. (1985). Changes in hemopoietic tissue of rainbow trout under influence of stress. Dis. aquat. Org. 1: $1-10$

Plytycz, B., Flory, C. M., Galvan, I., Bayne, C. J. (1989).

Responsible Subject Editor: W. Körting, Hannover, Germany
Leucocytes of rainbow trout (Oncorhynchus mykiss) pronephros: cell types producing superoxide anion. Dev. comp. Immunol. 13: 217-224

Richards, D. T., Hoole, D., Lewis, J. W., Ewens, E., Arme, C. (1994). Ultrastructural observations on the cellular response of carp (Cyprinus carpio L.) to eggs of the blood fluke Sanguinicola inermis Plehn, 1905 (Trematoda: Sanguinicolidae). J. Fish Dis. 17: in press

Rijkers, G. I., Frederix-Wolters, E. M. H., Van Muiswinkel, W. B. (1980). The immune system of cyprinid fish. Kinetics and temperature dependence of antibody-producing cells in carp (Cyprinus carpio). Immunology 41: 91-97

Rowley, A. F., Hunt, T. C., Page, M., Mainwaring, G. (1988). Fish. In: Rowley, A. F. \& Ratcliffe, N. A. (eds.) Vertebrate blood cells. Cambridge University Press, Cambridge, p. $19-127$

Secombes, C. J., Manning, M. J. (1982). Histological changes in lymphoid organs of carp following injection of soluble or particulate antigens. Dev. comp. Immunol. (Suppl.) 2: $53-58$

Secombes, C. J., Manning, M. J., Ellis, A. E. (1982). The effect of primary and secondary immunization on the lymphoid tissues of the carp, Cyprinus carpio L. J. exp. Zool. 220: $277-287$

Sommerville, C., Iqbal, N. A. M. (1991). The process of infection, migration, growth and development of Sanguinicola inermis Plehn, 1905 (Digenea: Sanguinicolidae) in carp, Cyprinus carpio L. J. Fish Dis. 14: 211-219

Tatner, M. F. (1985). The migration of labelled thymocytes to the peripheral lymphoid organs in the rainbow trout, Salmo gairdneri Richardson. Dev. Comp. Immunol. 9: $85-91$

Taylor, M. J., Hoole, D. (1989). Ligula intestinalis (L.) (Cestoda: Pseudophyllidea): plerocercoid-induced changes in the spleen and pronephros of roach, Rutilus rutilus (L.), and gudgeon, Gobio gobio (L.). J. Fish Biol. 34: 583-596

Taylor, M. J., Hoole, D. (1993). Ligula intestinalis (L.) (Cestoda: Pseudophyllidea): polarization of cyprinid leucocytes as an indicator of host- and parasite-derived chemoattractants. Parasitology 107: 433-440

Williams, M. A., Hoole, D. (1992). Antibody response of the fish Rutilus rutilus to the metacestode of Ligula intestinalis. Dis. aquat. Org. 12: 83-89

Woo, P. T. K. (1987). Cryptobia and cryptobiasis in fishes. Adv. Parasitol. 26: 199-229

Manuscript first received: February 7, 1994

Revised version accepted: May 17, 1994 